\title{
Hospitalist Experiences, Practice, Opinions, and Knowledge Regarding Peripherally Inserted Central Catheters: Results of a National Survey
}

\author{
Vineet Chopra, MD, MSc ${ }^{1,2 *}$, Latoya Kuhn, MPH'1 , Scott A. Flanders, MD², Sanjay Saint, MD, MPH ${ }^{1,2}$, Sarah L. Krein, RN, PhD ${ }^{1,2}$
}

${ }^{1}$ Patient Safety Enhancement Program and the Center for Clinical Management Research, VA Ann Arbor Healthcare System, Ann Arbor, Michigan; ${ }^{2}$ Department of Internal Medicine, University of Michigan School of Medicine, Ann Arbor, Michigan.

BACKGROUND: A Michigan survey found variation in hospitalist-reported experience, practice, opinions, and knowledge related to peripherally inserted central catheters (PICCs). Whether these findings reflect a national trend is unknown.

OBJECTIVE: To investigate self-reported PICC practice among adult hospitalists in the United States.

METHODS: Society of Hospital Medicine-administered, anonymous, Web-based survey of practicing, adult, nonMichigan hospitalists.

RESULTS: Of the 2112 hospitalists who were sent an electronic invitation, 381 completed the online survey (18\%). Eighty-six percent of hospitalists reported having placed a PICC solely for venous access (vs specific indications such as long-term antibiotics or parenteral nutrition).
Eighty-two percent reported having cared for a patient who specifically requested a PICC. Only $25 \%$ of hospitalists reported examining PICCs for evidence of external problems, whereas $57 \%$ admitted to having, at least once, forgotten about the presence of a PICC. Only $9 \%$ of respondents knew that PICC tip verification was performed primarily to prevent venous thromboembolism. Finally, $42 \%$ of participants indicated that $10 \%$ to $25 \%$ of PICCs placed in their hospitals might be inappropriately placed and/or avoidable.

CONCLUSIONS: This national survey highlights several potential opportunities to improve hospitalist PICC practices. A research agenda dedicated to this issue is necessary to improve patient safety and hospital-based practice. Journal of Hospital Medicine 2013;8:635-638. (c) 2013 Society of Hospital Medicine
Peripherally inserted central catheters (PICCs) are central venous catheters that are inserted through peripheral veins of the upper extremities in adults. Because they are safer to insert than central venous catheters (CVCs) and have become increasingly available at the bedside through the advent of specially trained vascular access nurses, ${ }^{1}$ the use of PICCs in hospitalized patients has risen across the United States. ${ }^{2}$ As the largest group of inpatient providers, hospitalists play a key role in the decision to insert and subsequently manage PICCs in hospitalized patients. Unfortunately, little is known about national hospitalist experiences, practice patterns, or knowledge when it comes to these commonly used devices. Therefore, we designed a 10-question survey to investigate PICC-related practices and knowledge among adult hospitalists practicing throughout the United States.

\section{PATIENTS AND METHODS}

Questions for this survey were derived from a previously published study conducted across 10 hospitals

\footnotetext{
*Address for correspondence and reprint requests: Vineet Chopra, MD, North Campus Research Complex, Building 16, Room 432W, 2800 Plymouth Road, Ann Arbor, Ml 48109; Telephone: 734-936-5216; Fax: 734-936-8944; E-mail: vineetc@umich.edu

Additional Supporting Information may be found in the online version of this article.

Received: August 15, 2013; Revised: September 20, 2013; Accepted: September 23, 2013

2013 Society of Hospital Medicine DOI 10.1002/jhm.2095

Published online in Wiley Online Library (Wileyonlinelibrary.com).
}

in the state of Michigan. ${ }^{3}$ To assess external validity and test specific hypotheses formulated from the Michigan study, those questions with the greatest variation in response or those most amenable to interventions were chosen for inclusion in this survey.

To reach a national audience of practicing adult hospitalists, we submitted a survey proposal to the Society of Hospital Medicine's (SHM) Research Committee. The SHM Research Committee reviews such proposals using a peer-review process to ensure both scientific integrity and validity of the survey instrument. Because the survey was already distributed to many hospitalists in Michigan, we requested that only hospitalists outside of Michigan be invited to participate in the national survey. All responses were collected anonymously, and no identifiable data were collected from respondents. Between February 1, 2013 and March 15, 2013, data were collected via an email sent directly from the SHM to members that contained a link to the study survey administered using SurveyMonkey. To augment data collection, nonresponders to the original e-mail invitation were sent a second reminder e-mail midway through the study. Descriptive statistics (percentages) were used to tabulate responses. The institutional review board at the University of Michigan Health System provided ethical and regulatory approval for this study.

\section{RESULTS}

A total of 2112 electronic survey invitations were sent to non-Michigan adult hospitalists, with 381 
TABLE 1. Variations in Hospitalist Experience,

Practice, Opinions, and Knowledge Related to

Peripherally Inserted Central Catheters

\begin{tabular}{|c|c|}
\hline & Total $(\mathrm{N}=381)$ \\
\hline \multicolumn{2}{|l|}{ Hospitalist experiences related to PICCS } \\
\hline \multicolumn{2}{|l|}{$\begin{array}{l}\text { Among hospitalized patients you have cared for, have any of your patients } \\
\text { ever had a PICC placed solely to obtain venous access (eg, not for an indi- } \\
\text { cation such as long-term IV antibiotics, chemotherapy, or TPN)? }\end{array}$} \\
\hline Yes & $328(86.1 \%)$ \\
\hline № & $53(13.9 \%)$ \\
\hline \multicolumn{2}{|l|}{$\begin{array}{l}\text { Have you ever cared for a patient who specifically requested a PICC because } \\
\text { of prior experience with this device? }\end{array}$} \\
\hline Yes & $311(81.6 \%)$ \\
\hline No & $70(18.4 \%)$ \\
\hline \multicolumn{2}{|l|}{ Most frequently encountered PICC complications } \\
\hline Upper-extremity DVT or PE & $48(12.6 \%)$ \\
\hline Bloodstream infection & $41(10.8 \%)$ \\
\hline Superficial thrombophlebitis & $34(8.9 \%)$ \\
\hline Cellulitis/exit site erythema & $26(6.8 \%)$ \\
\hline Colling, kinking of the PICC & $14(3.7 \%)$ \\
\hline Migration of the PICC tip & $9(2.4 \%)$ \\
\hline $\begin{array}{l}\text { Breakage of PICC (anywhere) } \\
\text { Hospitalist practice related to PICCS }\end{array}$ & $6(1.6 \%)$ \\
\hline \multicolumn{2}{|l|}{$\begin{array}{l}\text { During patient rounds, do you routinely examine PICCs for external problems } \\
\text { (eg, cracks, breaks, leaks, or redness at the insertion site)? }\end{array}$} \\
\hline Yes, daily & $97(25.5 \%)$ \\
\hline Yes, but only if the nurse or patient alerts me to a problem with the PICC & $190(49.9 \%)$ \\
\hline No, I don't routinely examine the PICC for external problems & $94(24.7 \%)$ \\
\hline \multicolumn{2}{|l|}{ Have you ever forgotten or been unaware of the presence of a PICC? } \\
\hline Yes & $216(56.7 \%)$ \\
\hline No & $165(43.3 \%)$ \\
\hline \multicolumn{2}{|l|}{$\begin{array}{l}\text { Assuming no contraindications exist, do you anticoagulate patients who } \\
\text { develop a PICC-associated DVT? }\end{array}$} \\
\hline Yes, for at least 1 month & $41(10.8 \%)$ \\
\hline Yes, for at least 3 months* & $198(52.0 \%)$ \\
\hline Yes, for at least 6 months & $11(2.9 \%)$ \\
\hline $\begin{array}{l}\text { Yes, I anticoagulate for as long as the line remains in place. Once the line } \\
\text { is removed, I stop anticoagulation }\end{array}$ & $30(7.9 \%)$ \\
\hline $\begin{array}{l}\text { Yes, I anticoagulate for as long as the line remains in place followed by } \\
\text { another } 4 \text { weeks of therapy }\end{array}$ & $72(18.9 \%)$ \\
\hline I don't usually anticoagulate patients who develop a PICC-related DVT & $29(7.6 \%)$ \\
\hline \multicolumn{2}{|l|}{$\begin{array}{l}\text { When a hospitalized patient develops a PICC-related DVT, do you routinely } \\
\text { remove the PICC? }\end{array}$} \\
\hline Yes & $271(71.1 \%)$ \\
\hline No & $110(28.9 \%)$ \\
\hline \multicolumn{2}{|l|}{ Hospitalist opinions related to PICCS } \\
\hline \multicolumn{2}{|l|}{$\begin{array}{l}\text { Thinking about your hospital and your experiences, what percentage of PICC } \\
\text { insertions may represent inappropriate use (eg, PICC placed for short- } \\
\text { term venous access for a presumed infection that could be treated with } \\
\text { oral antibiotic or PICCs that were promptly removed as the patient no lon- } \\
\text { ger needed it for clinical management)? }\end{array}$} \\
\hline$<10 \%$ & $192(50.4 \%)$ \\
\hline $10 \%-25 \%$ & $160(42.0 \%)$ \\
\hline $26 \%-50 \%$ & $22(5.8 \%)$ \\
\hline$>50 \%$ & $7(1.8 \%)$ \\
\hline \multicolumn{2}{|l|}{ Do you think hospitalists should be trained to insert PICCs? } \\
\hline Yes & $162(42.5 \%)$ \\
\hline № & $219(57.5 \%)$ \\
\hline
\end{tabular}

completing the online survey (response rate 18\%). Among respondents to the national survey, $86 \%$ reported having placed a PICC solely to obtain venous access in a hospitalized patient (rather than for specific
TABLE 1. Continued

Total $(\mathrm{N}=381)$

Hospitalist knowledge related to PICCS

Why is the position of the PICC-tip checked following bedside PICC insertion?

To decrease the risk of arrhythmia from tip placement in the right atrial $\quad 267(70.1 \%)$

To ensure it is not accidentally placed into an artery $44(11.5 \%)$

To minimize the risk of venous thrombosis ${ }^{*} \quad 33(8.7 \%)$

For documentation purposes (to reduce the risk of lawsuits related $\quad 16(4.2 \%)$

tocomplications)

I don't know

$21(5.5 \%)$

NOTE: Abbreviations: DVT, deep venous thrombosis; IV, intravenous; PE, pulmonary embolism; PICC, peripherally inserted central catheter; TPN, total parenteral nutrition. ${ }^{*}$ Correct answer.

indications such as long-term intravenous antibiotics, chemotherapy, or parenteral nutrition), whereas $82 \%$ reported having cared for a patient who specifically requested a PICC (Table 1). PICC-related deep vein thrombosis (DVT) and bloodstream infections were reported as being the most frequent PICC complications encountered by hospitalists, followed by superficial thrombophlebitis and mechanical complications such as coiling, kinking, and migration of the PICC tip.

Several potentially important safety concerns regarding hospitalist PICC practices were observed in this survey. For instance, only $25 \%$ of hospitalists reported examining PICCs on daily rounds for external problems. When alerted by nurses or patients about problems with the device, this number doubled to $50 \%$. In addition, $57 \%$ of respondents admitted to having at least once forgotten about the presence of a PICC in their hospitalized patient.

Participants also reported significant variation in duration of anticoagulation therapy for PICC-related DVT, with only half of all respondents selecting the guideline-recommended 3 months of anticoagulation. ${ }^{4,5}$ With respect to knowledge regarding PICCs, only $9 \%$ of respondents recognized that tip verification performed after PICC insertion was conducted to lower risk of venous thromboembolism, not that of arrhythmia. ${ }^{6}$ Hospitalists were ambivalent about being trained on how to place PICCs, with only $43 \%$ indicating this skill was necessary. Finally, as many as $10 \%$ to $25 \%$ of PICCs inserted in their hospitals were felt to be inappropriately placed and/or avoidable by $42 \%$ of those surveyed.

\section{DISCUSSION}

As the use of PICCs rises in hospitalized patients, variability in practices associated with the use of these indwelling vascular catheters is being increasingly recognized. For instance, Tejedor and colleagues reported that PICCs placed in hospitalized patients at their academic medical center were often idle or inserted in patients who simultaneously have peripheral intravenous catheters. ${ }^{7}$ Recent data from a tertiary care 
pediatric center found significantly greater PICC utilization rates over the past decade in association with shorter dwell times, suggesting important and dynamic changes in patterns of use of these devices. ${ }^{2}$ Our prior survey of hospitalists in 10 Michigan hospitals also found variations in reported hospitalist practices, knowledge, and experiences related to PICCs. ${ }^{3}$ However, the extent to which the Michigan experience portrayed a national trend remained unclear and was the impetus behind this survey. Results from this study appear to support findings from Michigan and highlight several potential opportunities to improve hospitalist PICC practices on a national scale.

In particular, $57 \%$ of respondents in this study (compared to $51 \%$ of Michigan hospitalists) stated they had at least once forgotten that their patient had a PICC. As early removal of PICCs that are clinically no longer necessary is a cornerstone to preventing thrombosis and infection, ${ }^{4-6,8}$ the potential impact of such forgetfulness on clinical outcomes and patient safety is of concern. Notably, PICC-related DVT and bloodstream infection remained the 2 most commonly encountered complications in this survey, just as in the Michigan study.

Reported variations in treatment duration for PICCrelated DVT were also common in this study, with only half of all respondents in both surveys selecting the guideline-recommended minimum of 3 months of anticoagulation. Finally, a substantial proportion $(42 \%)$ of participants felt that $10 \%$ to $25 \%$ of PICCs placed in their hospitals might be inappropriately placed and avoidable, again echoing the sentiments of $51 \%$ of the participants in the Michigan survey. These findings strengthen the call to develop a research agenda focused on PICC use in hospitalized patients across the United States.

Why may hospitalists across the country demonstrate such variability when it comes to these indwelling vascular devices? PICCs have historically been viewed as safer with respect to complications such as infection and thrombosis than other central venous catheters, a viewpoint that has likely promulgated their use in the inpatient setting. However, as we and others have shown, ${ }^{8-12}$ this notion is rapidly vanishing and being replaced by the recognition that severity of illness and patient comorbidities are more important determinants of complications than the device itself. Additionally, important knowledge gaps exist when it comes to the safe use of PICCs in hospitalized patients, contributing to variation in indications for insertion, removal, and treatment of complications related to these devices.

Our study is notably limited by a low response rate. Because the survey was administered directly by SHM without collection of respondent data (eg, practice location, years in practice), we are unable to adjust or weight these data to represent a national cohort of adult hospitalists. However, as responses to questions are consistent with our findings from Michigan, and the response rates of this survey are comparable to observed response rates from prior SHM-administered nationwide surveys $(10 \%-40 \%),{ }^{13-15}$ we do not believe our findings necessarily represent systematic deviations from the truth and assumed that these responses were missing at random. In addition, owing to use of a survey-based design, our study is inherently limited by a number of biases, including the use of a convenience sample of SHM members, nonresponse bias, and recall bias. Given these limitations, the association between the available responses and real-world clinical practice is unclear and deserving of further investigation.

These limitations notwithstanding, our study has several strengths. We found important national variations in reported practices and knowledge related to PICCs, affirming the need to develop a research agenda to improve practice. Further, because a significant proportion of hospitalists may forget their patients have PICCs, our study supports the role of technologies such as catheter reminder systems, computerized decision aids, and automatic stop orders to improve PICC use. These technologies, if utilized in a workflow-sensitive fashion, could improve PICC safety in hospitalized settings and merit exploration. In addition, our study highlights the growing need for criteria to guide the use of PICCs in hospital settings. Although the Infusion Nursing Society of America has published indications and guidelines for use of vascular devices, ${ }^{6}$ these do not always incorporate clinical nuances such as necessity of intravenous therapy or duration of treatment in decision making. The development of evidence-based appropriateness criteria to guide clinical decision making is thus critical to improving use of PICCs in inpatient settings. ${ }^{16}$

With growing recognition of PICC-related complications in hospitalized patients, an urgent need to improve practice related to these devices exists. This study begins to define the scope of such work across the United States. Until more rigorous evidence becomes available to guide clinical practice, hospitals and hospitalists should begin to carefully monitor PICC use to safeguard and improve patient safety.

Disclosures: The Blue Cross/Blue Shield of Michigan Foundation funded this study through an investigator-initiated research proposal (1931PIRAP to Dr. Chopra). The funding source played no role in study design, acquisition of data, data analysis, or reporting of these results. The authors report no conflicts of interest.

\section{References}

1. Wojnar DG, Beaman ML. Peripherally inserted central catheter: compliance with evidence-based indications for insertion in an inpatient setting. J Infus Nurs. 2013;36(4):291-296.

2. Gibson C, Connolly BL, Moineddin R, Mahant S, Filipescu D, Amaral JG. Peripherally inserted central catheters: use at a tertiary care pediatric center. J Vasc Interv Radiol. 2013;24(9):1323-1331.

3. Chopra V, Kuhn L, Coffey CE Jr, et al. Hospitalist experiences, practice, opinions, and knowledge regarding peripherally inserted central catheters: a Michigan survey. J Hosp Med. 2013;8(6):309-314.

4. Guyatt GH, Akl EA, Crowther M, et al. Executive summary: antithrombotic therapy and prevention of thrombosis, 9th ed: American College of Chest Physicians evidence-based clinical practice guidelines. Chest. 2012;141(2 suppl):7S-47S. 
5. Dariushnia SR, Wallace MJ, Siddiqi NH, et al. Quality improvement guidelines for central venous access. J Vasc Interv Radiol. 2010;21(7): 976-981.

6. Gorsky LA, Eddins J, Hadaway L, et al. Infusion nursing standards of practice. J Infus Nurs. 2011;34(1S):1-115.

7. Tejedor SC, Tong D, Stein J, et al. Temporary central venous catheter utilization patterns in a large tertiary care center: tracking the "idle central venous catheter". Infect Control Hosp Epidemiol. 2012;33(1):50-57.

8. Chopra V, Anand S, Hickner A, et al. Risk of venous thromboembolism associated with peripherally inserted central catheters: a systematic review and meta-analysis. Lancet. 2013;382(9889):311-325.

9. Jumani K, Advani S, Reich NG, Gosey L, Milstone AM. Risk factors for peripherally inserted central venous catheter complications in children. JAMA Pediatr. 2013;167(5):429-435.

10. Pongruangporn M, Ajenjo MC, Russo AJ, et al. Patient- and device-specific risk factors for peripherally inserted central venous catheter-related bloodstream infections. Infect Control Hosp Epidemiol. 2013;34(2):184-189.

11. Chopra V, O'Horo JC, Rogers MA, Maki DG, Safdar N. The risk of bloodstream infection associated with peripherally inserted central catheters compared with central venous catheters in adults: a systematic review and meta-analysis. Infect Control Hosp Epidemiol. 2013; 34(9):908-918.

12. Safdar N, Maki DG. Risk of catheter-related bloodstream infection with peripherally inserted central venous catheters used in hospitalized patients. Chest. 2005;128(2):489-495.

13. Hinami K, Whelan CT, Miller JA, Wolosin RJ, Wetterneck TB; Society of Hospital Medicine Career Satisfaction Task Force. Job characteristics, satisfaction, and burnout across hospitalist practice models. J Hosp Med. 2012;7(5):402-410.

14. Goodman PH, Januska A. Clinical hospital medicine fellowships: perspectives of employers, hospitalists, and medicine residents. J Hosp Med. 2008;3(1):28-34.

15. Harrison R, Hunter AJ, Sharpe B, Auerbach AD. Survey of US academic hospitalist leaders about mentorship and academic activities in hospitalist groups. J Hosp Med. 2011;6(1):5-9.

16. Chopra V, Flanders SA, Saint S. The problem with peripherally inserted central catheters. JAMA. 2012;308(15):1527-1528. 